\title{
PRACTICE
}

\section{Leveraging a Large Database to Increase Access to Undergraduate Research Experiences}

\author{
Laura A. Lukes, George Mason University \\ Katherine Ryker, University of South Carolina \\ Camerian Millsaps, George Mason University \\ Rowan Lockwood, William and Mary \\ Mark D. Uhen, George Mason University \\ Christian George, High Point University \\ Callan Bentley, Northern Virginia Community College \\ Peter Berquist, Thomas Nelson Community College
}

\begin{abstract}
Undergraduates who participate in research experiences are more likely to persist as majors and pursue careers in STEM fields. Traditional undergraduate research experiences often involve field or lab work, which can be costly or have participation barriers for some students. Large, publicly available online datasets provide an alternative. This article provides a case study of how one such large database, the Paleobiology Database (PBDB), has been leveraged in two ways to support the engagement of students in undergraduate research experiences. First, the authors report on inquiry-based PBDB activities embedded within introductory science courses and participating students' perceptions about research and interest in research $(n=264)$. Second, they report how the PBDB has been used to support independent research experiences across 19 institutions and share implications.
\end{abstract}

Keywords: data sets, inquiry-based activities, Paleobiology Database, STEM education, student perceptions, undergraduate research

doi: $10.18833 /$ spur/2/4/6

Undergraduate students who participate in research experiences are more likely to persist as STEM majors and pursue careers in STEM fields (National Academies of Sciences, Engineering, and Medicine 2016, 2017), meeting a national need for a qualified STEM workforce (National Academies of Sciences, Engineering, and Medicine 2018). However, traditional undergraduate research experiences that involve field or lab work can be costly or have in-person time requirements that present barriers for nontraditional students such as first-generation students, students who are career changers, students transferring from two-year colleges, students with family or outside work responsibilities, or students with disabilities (Baker 2006; Carabajal, Marshall, and Atchison 2018; Drummond 2001; Whitmeyer, Mogk, and Pyle 2009). Additionally, two-year colleges and smaller universities may not have access to lab equipment or field sites necessary for these traditional versions of undergraduate research experiences (Birnbaum 2004; Hurst 1998; Kean and Enochs 2001). The use of large, publicly available online datasets provides an alternative to traditional undergraduate research experiences.

\section{Motivation and Research Questions}

How can these large databases be leveraged to provide robust and meaningful research experiences for undergraduate students who would otherwise be unable to engage in undergraduate research? Despite the increasing availability of such databases, surprisingly little has been reported on how they have affected student access to research experiences (Singer, Nielsen, and Schweingruber 2012). Although answering this broad question is beyond the scope presented here, this article serves as a first step by providing a case study of how one such large database, the Paleobiology Database (PBDB n.d.a), has been used to support the engagement of students in undergraduate 
research experiences as part of (1) inquiry-based course activities and (2) independent research experiences. Specifically, the authors examined student perceptions of research and their future interest in using the PBDB to conduct independent research after experiencing inquirybased activities using the PBDB embedded in introductory geoscience courses. Also explored was the nature of independent undergraduate research projects using the PBDB across the geoscience community to determine if such projects could result in student success as measured by peer-reviewed presentations and publications.

\section{The Paleobiology Database and Affiliated Inquiry-Based Activities}

To explore the viability of using large databases for undergraduate research, the authors examined student use of the PBDB. PBDB includes a web portal that provides access to data on fossil organisms across geologic time and global location. It is used extensively by researchers and was originally constructed to help answer questions about the evolution of diversity of life on Earth and its relationship with geological processes. The database includes more than 1.4 million fossil occurrences, 68,000 references, and 384,000 taxonomic names. PBDB also includes a more general audience data-visualization tool, PBDB Navigator, that allows users to visually interact with the data on a global map, as well as a data services system for user development of independent analytical tools, visualization software, and other applications (Uhen 2014, 2015, 2016).

The database and the PBDB Navigator were leveraged to create inquiry-based lesson activities for use within a variety of courses at the high school to graduate level (e.g., physical and historical geology, biology, paleontology, stratigraphy) to support students in their inquiry skill development, comfort with datasets and cyberinfrastructure, and future interest in conducting research projects. In other words, the project focused on skill preparation to conduct independent research. Inquiry-based learning enjoys a wide variety of modifiers and definitions (see Buck, Bretz, and Towns 2008); here, the definition used is from the National Research Council (2000), which states that inquiry-based activities parallel the process of science and ask students to be involved in the asking of scientifically oriented questions, prioritize evidence to answer those questions, formulate explanations using that evidence, connect explanations to the current body of scientific knowledge, and meaningfully communicate those explanations. The development of freely available, inquiry-based course activities is important, as overall introductory geology lab activities have been found to have low levels of inquiry (Buck, Bretz, and Towns 2008; Ryker and McConnell, 2014). If students engage in inquiry-based activities at more levels of undergraduate coursework, they are gaining important practice with skills that will support them in conducting their own scientific research.
The activities described here are designed to be modular in nature so that they can be adopted as lecture, homework, or lab activities, ranging in duration from five minutes to three hours, in online or face-to-face courses. The overarching goal of these activities is to develop scientifically literate citizens and scaffold student skill development for conducting independent research. The activities cover common topics for geoscience courses, such as plate tectonics, diversity and extinction rates, and climate. They address inquiry-based skill learning outcomes such as predicting variable relationships, developing and testing hypotheses, creating data plots, and interpreting data, as well as conceptual learning outcomes (e.g., determining whether a fossil sample is a body or trace fossil, explaining which types of fossils are useful for biostratigraphy, or determining characteristics of organisms that lead to understanding the water depth of their habitat). The full learning outcomes for each activity are described in Table 1 and included with each lesson. In total, eight lesson activities were developed, and six are publicly available through the PBDB Resources webpage (PBDB n.d.b) and the Science Education Resource Center (SERC) educational resource platform (Carleton College n.d., search term PBDB). The full pedagogical description of three of these activities and their content is discussed by Lockwood and colleagues (2018); here, the focus is on activity development and the peer review vetting process as a model.

Each lesson plan was initially conceived and authored by an introductory geoscience course instructor (Rowan Lockwood from William and Mary, Mark D. Uhen from George Mason University, Callan Bentley from Northern Virginia Community College, Christian George from High Point University, and Peter Berquist from Thomas Nelson Community College) and went through a multistage peer-review vetting process adapted from InTeGrate (2016). The vetting process consisted of five phases: (1) initial review and feedback provided by two professional education researchers (authors Lukes and Ryker), (2) author revision and completion of a self-evaluation copy of the rubric, (3) secondary review by the same professional education researchers using the established rubric to ensure that a baseline minimum score had been met, (4) field testing in courses, and (5) final revisions based on practitioner observations. Steps 2 and 3 were repeated as needed to ensure that the lesson met at least the minimum score in each of the rubric categories. The Evaluating the Quality of Assignments and Activities Rubric (Tewksbury 2011) was selected to evaluate activities because it is an established and vetted tool. This rubric was used throughout the activity vetting process. It includes four categories (student engagement, scientific accuracy, goal-assessment alignment, and ease of use by others) in a Likert scale format (no, a little, somewhat, or definitely, numbered 1 to 4 , respectively). The rubric includes guidelines regarding minimum score targets to determine activity quality. The 
TABLE 1. Learning Outcome Goals for Inquiry-Based Activities Created Using the Paleobiology Database

\begin{tabular}{|c|c|}
\hline Activity Name & Learning outcomes \\
\hline Counting Critters & $\begin{array}{l}\text { Students will be able to: } \\
\text { - Construct a diversity curve using data and tools from PBDB Navigator (Part 1) } \\
\text { - Interpret graphical representations of diversity curves to identify possible increases and decreases in } \\
\text { diversity (Part 1) } \\
\text { - Identify a major origination (Cambrian Explosion) graphically and use internet sources to research } \\
\text { its possible causes (Part 1) } \\
\text { - Identify a major extinction (end-Permian Extinction) graphically and use internet sources to research } \\
\text { a possible cause (Part 1) } \\
\text { - Assess the effects of sampling and preservation on quantifying diversity (Part 2) } \\
\text { - Assess the extent to which diversity patterns are affected by the inclusion of singleton taxa (Part 2) }\end{array}$ \\
\hline Fossils Under Your Feet & $\begin{array}{l}\text { Students will be able to: } \\
\text { - Estimate what percentage of their state/province is represented by data in the PBDB } \\
\text { - Describe where fossil organisms have been found in their local county } \\
\text { - List which fossil phyla (plural of phylum) have been found in their local county } \\
\text { - Research the common names of organisms classified in those phyla } \\
\text { - Research when and where one particular species (their choice) lived in the fossil record } \\
\text { - Determine whether that species was a body or trace fossil } \\
\text { - Figure out whether that species is extinct or still living today } \\
\text { - Research what that species looked like, how it fed (if applicable), and its habitat, etc. } \\
\text { - Determine the geologic age of a fossil locality in their local county }\end{array}$ \\
\hline The Panama Passageway & $\begin{array}{l}\text { Students will be able to: } \\
\text { - Generate maps showing the distribution of perissodactyls and glyptodonts for four different epochs } \\
\text { of the Cenozoic Era } \\
\text { - Interpret these maps in terms of their tectonic implications } \\
\text { - Test their interpretation with a suite of other relevant fossil organisms } \\
\text { - Test their interpretation with a set of relevant paleogeographic maps } \\
\text { - Apply these techniques to other regions, times, and species, and use the PBDB to test these ideas } \\
\text { (although not necessarily conclusively) }\end{array}$ \\
\hline The Pangaea Puzzle & $\begin{array}{l}\text { Students will be able to: } \\
\text { - Construct a map of fossil occurrences on the present-day Earth's surface } \\
\text { - Construct a map of fossil occurrences on the Earth's surface at various times in Earth's past } \\
\text { - Identify the past distributions of fossils on ancient continents and supercontinents } \\
\text { - Explain how the present-day distributions of fossil organisms is different from their distribution during } \\
\text { the time of their deposition as fossils } \\
\text { - Develop hypotheses regarding why the present-day distribution of fossil occurrences is dramatically } \\
\text { different from their distribution during the time of their deposition as fossils }\end{array}$ \\
\hline $\begin{array}{l}\text { Life through Time: } \\
\text { Investigating } \\
\text { Biostratigraphy with the } \\
\text { PBDB }\end{array}$ & $\begin{array}{l}\text { Students will be able to: } \\
\text { - Define the Principle of Faunal Succession } \\
\text { - Explain which types of fossils are useful for biostratigraphy and why } \\
\text { - Define what an index fossil is and which fossils make good index fossils }\end{array}$ \\
\hline $\begin{array}{l}\text { Tracking Sea Level and } \\
\text { Paleoenvironments with } \\
\text { Fossils }\end{array}$ & $\begin{array}{l}\text { Students will be able to: } \\
\text { - Identify coastal/near-shore depositional environments } \\
\text { - Determine suitable and desirable characteristics of organisms that lead to understanding water depth of } \\
\text { their habitat } \\
\text { - Create maps showing the spatial and temporal distribution of specific fossils } \\
\text { - Create paleogeographic reconstructions for the Cretaceous, Paleogene, and Neogene Periods of } \\
\text { southeastern North America } \\
\text { - Interpret environmental changes for an area based on the spatial and temporal change of its fossils } \\
\text { - Describe the extent and rate of sea-level change within an area over a specific time frame, based on } \\
\text { observation of changes in the fossil record } \\
\text { - Predict causal mechanisms for sea-level change within a specified time and area } \\
\text { - Predict additional organisms that could be used to identify sea-level change in other areas and use the } \\
\text { PBDB Navigator to test these predictions }\end{array}$ \\
\hline
\end{tabular}


TABLE 1. (cont.)

\begin{tabular}{|l|l|}
\hline $\begin{array}{l}\text { How Is Whale Diversity } \\
\text { Affected by Climate }\end{array}$ & $\begin{array}{l}\text { Students will be able to: } \\
\text { - Use the PBDB Navigator to create diversity curves for whales throughout the Cenozoic } \\
\text { - Develop testable and plausible hypotheses explaining changes in whale diversity based on diversity curves } \\
\text { - Describe how } \delta 180 \text { data are used to interpret past climatic conditions } \\
\text { - Interpret Cenozoic } \delta 18 \text { O data from benthic sediments, with a focus on climatic changes } \\
\text { - Compare the changes in diversity of whales with } \delta 180 \text { throughout the Cenozoic }\end{array}$ \\
\hline $\begin{array}{l}\text { Measuring Mass } \\
\begin{array}{l}\text { Extinctions: Quantifying } \\
\text { Using the Paleobiology } \\
\text { Database }\end{array}\end{array}$ & $\begin{array}{l}\text { Students will be able to: } \\
\text { - Construct extinction rate curves and analyze them graphically using PBDB (Part 1) } \\
\text { - Identify mass extinctions graphically and distinguish them from background extinction (Part 1) } \\
\text { - Estimate the magnitude of the Permian/Triassic extinction using an extinction rate plot (Part 2) } \\
\text { - Identify three possible causes of the Permian/Triassic extinction and evaluate their likelihood using inter- } \\
\text { net sources (Part 2) }\end{array}$ \\
$\begin{array}{l}\text { - Design a study to test one cause of the Permian/Triassic extinction based on fossil data (Part 2) } \\
\text { - Detect periodicity in patterns of extinction by examining a plot of extinction rates (Part 3) }\end{array}$
\end{tabular}

Note $:$ PBDB $=$ Paleobiology Database .

use of this rubric with its minimum score targets ensured that the final activities would be well written, usable, and aligned with the stated learning objectives and goals of the project.

\section{Participants and Institutions}

This exploratory investigation describes a case study of students using the PBDB. Specifically, the study examines two populations: (1) a population of undergraduate students engaged in inquiry-based activities and (2) a population of undergraduate students who used the PBDB as part of an independent research experience, as reported by faculty members. For the first population, the activities were incorporated into introductory geoscience and bioscience courses by 264 students across five institutions (3 four-year and 2 two-year colleges). Demographic data was self-reported as part of an end of course survey. Respondents primarily identified as female (61 percent), with the rest identifying as male (38 percent) or other/blank (1 percent). Consistent with representation in the geosciences (Bernard and Cooperdock 2018), students were overwhelmingly white (76 percent), followed by Asian ( 8 percent), black or African American (5 percent), Hispanic or Latinx ( 5 percent), or more than one race (3 percent). The remaining 3 percent of the study participants identified as American Indian, Native Alaskan, other, or left the field blank. The majority were of traditional college student ages (18-22; 93 percent), with representation across academic ranks (25 percent first-year students; 31 percent second-year students; 22 percent third-year students; 15 percent fourth-year students; 6 percent other). The majority (80 percent) also reported that they had one or more parent or legal guardian who completed a bachelor's degree, indicating that they were not first-generation students. Only 18 (7 percent) reported attending a two-year college; 78 percent of those students planned to eventually transfer to a four-year institution. In terms of majors, 59 percent reported that they planned to major in science ( 35 percent said no; 6 percent maybe). Regarding future plans, 55 percent reported they planned to "go to graduate school for an advanced degree" as their primary long-term professional goal after graduation; 33 percent reported they planned to "seek employment in a field related to their major."

For the second population, those students engaged in independent research experiences using the PBDB, survey data about students was collected from faculty across the geoscience community rather than directly from participating students due to barriers to locating students. Demographic data were not collected as part of the survey data because faculty might not have had that information, as well as to reduce concerns about inaccuracies with comparison to self-reported data. Data were collected from 18 faculty members who reported a total of approximately 100 students engaged in research projects that used PBDB at some point between 2008 and the present. Research projects were reported as having taken place across 19 institutions in the United States (17) and other countries (2). One faculty member reported student projects at two different institutions. All projects were reported as being completed by students at four-year institutions.

\section{Assessment Process}

To examine student interest in using the PBDB specifically to conduct independent research in the future, students first completed inquiry-based activities using the PBDB embedded in their introductory geoscience courses. This was done to expose them to the database in ways that allowed them to develop or practice applying research skills, such as using their scientific knowledge to explain trends in fossil types over time. Because the activities were incorporated across a variety of course designs and activity implementation timelines, it was impractical to assess the direct impact of these activities on student perceptions and interest. Instead, the authors sought to capture a snapshot of future interest in conducting research with the PBDB in the context 
of their general perceptions of what constituted research. Open-ended reflection questions were included as part of the activities to capture immediate student perceptions about and interest in using the PBDB to conduct research. The relevant questions included the following: "Now that you have used the database for this activity, how could you use this database to create your own research project?" and "Would you want to use this database to create/conduct your own research project? Why or why not?" The responses to these questions were axially and selectively coded (Strauss and Corbin 1998) by the primary author (Lukes) and cocoded by an undergraduate researcher using the inter-rater approach of Gorden (1992).

To provide further details on the general perceptions of research these students had experienced, students participating in these courses and activities were asked to complete a survey during the last week of class. The survey was part of a larger investigation of the value of PBDB-related learning activities and used existing, validated instruments, the Student Assessment of Learning Gains (SALG 2013; Seymour et al. 2000) and the OSCAR (Office for Student Scholarship, Creative Activities, and Research) Student Survey (Foster and Usher 2018). These instruments were designed to examine student perceptions of what they learned and of research and research-related skills as well as to capture demographic data. Only data that specifically addressed student perceptions of research and demographic data are reported here. These questions came from the OSCAR instrument and were selected because of their topical relevance, prior validation, and common use for future comparisons. Two questions were multiple choice, and the remaining nine questions presented students with statements about the value of research activities and asked them to report the degree to which they agreed with the statements using a four-point Likert scale (strongly agree, agree, disagree, strongly disagree).

Although the PBDB activities described above were inquiry-based, they were not independent research projects in which students developed and implemented their own research questions and methods. In order to explore how the PBDB was being used in independent research experiences, students working on such projects using the PBDB first had to be identified. An exploratory survey asked faculty in the geoscience community to list and describe any student research projects they mentored or supervised that involved the use of PBDB. They were also asked to report indicators of success in the form of peer-reviewed presentations and publications. The survey was sent to registered PBDB members, authors of official PBDB publications, and broader community listserves (e.g., the National Association of Geoscience Teachers, the Geoscience Education Division of Geological Society of America, and the Paleontological Society) and social media. It was also shared during PBDB-related workshops and professional presentations. A more detailed follow-up survey was created and sent to responding faculty in an effort to follow up with students directly; however, no responses to this follow-up survey were received, limiting the data.

\section{Results}

\section{Inquiry-Based Activity Reflection Questions}

Written activity reflection question data were collected from 189 students at 5 institutions ( 3 four-year and 2 twoyear institutions) across six vetted activities from fall 2016 to fall 2017. When asked if students would want to use the PBDB to create or conduct their own research project, the majority of students responded yes (61 percent), with an additional 11 percent reporting yes, if there was a qualifying factor such as a required research assignment or if it made sense to use the PBDB tool with the project of interest. The 16 percent who responded no cited limitations or negative experience with the PBDB tool or a lack of interest in the topic. The remaining 12 percent of responses were blank or conceptually unclear. The 61-percent majority who reported yes and provided a rationale cited positive experiences with the PBDB tool, an interest in the topic, or a general willingness to use the tool despite its limitations or their negative experience with the tool.

When students were asked how they could use the PBDB to create their own research project, there was a range of response quality and clarity. Almost one-third (31 percent) of the responses were conceptually unclear or left blank. Less than 1 percent of the responses described using the PBDB in different ways: to identify a field site for a research project $(n=5)$ or to conduct a computer science or database research project. The majority of the responses reflected two themes: descriptive projects $(25$ percent, $n=48$ ) and relational projects (43 percent, $n=$ $82)$. The descriptive research projects were reported by students who used the PBDB to make observations or to collect data (e.g., to determine where fossils were at given time; to see what species were present; to find species information). For the relational research projects, students reported using the PBDB to ask a question (e.g., how did $\mathrm{X}$ change over time) or to explore a variable relationship or develop a hypothesis (e.g., to find out why $\mathrm{X}$ changed over time; to identify a correlation between $\mathrm{X}$ and $\mathrm{Y}$ ).

\section{Inquiry-Based Activity Survey}

The survey students completed at the end of their course included questions from the OSCAR instrument. One multiple-choice question asked students about conducting research: "Outside of regular course assignments, have you done or do you plan to do a research or creative activity/project with a faculty member before graduation?" The majority, 45 percent (119 of 264), reported that "outside of regular course assignments" they had done or planned to do "a research or creative activity/project with 
a faculty member before graduation," with an additional 32 percent reporting that they were not sure and 23 percent reporting no. For a follow-up multiple choice question that asked students what would motivate them to do their own research project, students $(n=263)$ reported a range of motivators, including "working on a specific project of interest" (76 percent), "gaining experience for career or graduate school" (71 percent), "being excited or loving the work" (59 percent), "working on a project that might contribute to individual or community well-being" (49 percent), "receiving compensation or pay" (45 percent), "working on a project with a specific faculty member" (43 percent), "being required by my major or degree" (40 percent), "meeting peers who have similar interests or goals" (28 percent), and "other" ( 3 percent). Only 2 people (less than 1 percent) reported that "nothing would motivate them to participate" in research.

Using a four-point Likert scale (strongly agree, agree, disagree, or strongly disagree), students were also asked to report the degree to which they agreed with nine statements about the value of research activities (see Table 2). Responses were strongly positive, with 94 to 97 percent reporting "agree" to "strongly agree" on all researchpositive statements such as "advances in research can solve real-life problems," "learning about research or creative works makes me more curious about the world," and "being involved in research or creative activities can help me become a better professional in my field." Twenty percent or fewer agreed or strongly agreed with the research-negative items included, such as "most research focuses on problems that are too insignificant to really mean anything" and "helping a professor with his/her research would be a waste of my time." One-way ANOVA revealed no significant difference in attitudes toward research between students identifying as a STEM majors, non-STEM majors, or potential STEM majors (unsure) $(\mathrm{F}(2,261)=0.48365, p=0.61)$.

\section{Independent Research Experiences Survey}

Faculty reported 36 students by name as engaged in independent research projects using the PBDB. A few of the faculty respondents (four) reported more generally: "27 NSF-funded REU students in [specific program]," "dozens of students in class research project," "[specific class] of 22 students," and "various students." The level of detail reported about the nature of the approximately 100 student research projects was varied. Some respondents reported basic project concepts (e.g., "brachiopod body size evolution"), whereas others described in detail the question explored or hypothesis tested, data used, how data were analyzed or used, and conclusions drawn. Many of the projects were reported to involve students compiling data of particular organisms to explore relationships between organism or morphology distribution over time, determine record completeness for a species, or monitor changes in morphology over time to examine evolution and survivorship patterns. Two projects reportedly used data to determine if there was sampling bias in the fossil record: one looked at the proximity of fossil sites in the PBDB to road locations, and the other explored the nature and frequency of depositional environments associated with the fossil sites.

To determine research experience value, the study used a metric of the number of reported student presentations or publications from research using PBDB as an indicator

\section{TABLE 2. Student Self-Report Survey Results}

\begin{tabular}{|l|c|}
\hline Please rate your level of agreement with each of the following statements: & $\begin{array}{c}\text { Percentage of "agree" or "strongly } \\
\text { agree" responses }\end{array}$ \\
\hline (1) Laws and policy decisions should be based on research findings. & $93.6 \%$ \\
\hline (2) Advances in research can solve real-life problems. & $97.0 \%$ \\
\hline (3) Being involved in research or creative activities can help me become a better professional \\
in my field. & $97.3 \%$ \\
\hline (4) Learning about proper research methods and techniques is a valuable use of time. & $95.1 \%$ \\
\hline (5) Participating in the creation or discovery of new knowledge is personally rewarding. & $97.0 \%$ \\
\hline (6) Helping a professor with her/his research would be a waste of my time. & $7.2 \%$ \\
\hline (7) Learning about research or creative works makes me more curious about the world. & $94.3 \%$ \\
\hline (8) Participating in research or creative activities improves academic experience. & $97.7 \%$ \\
\hline (9) Most research focuses on problems that are too insignificant to really mean anything. & $20.1 \%$ \\
\hline
\end{tabular}

Note: The table contains the portion of the survey related to student perceptions of research. This survey was administered to students who participated in the course-embedded Paleobiology Database (PBDB) inquiry-based activities. Students were asked to rate their level of agreement using a Likert scale (strongly agree, agree, disagree, or strongly disagree). 
of student success, with the rationale that communicating research in a public forum is a critical part of scientific research. Due to the general terms used by some survey participants in reporting projects, an indeterminate number (greater than 5) of student research projects were presented as class reports or presentations, or honors thesis papers. Eighteen institutional- or regional-level student symposium presentations were specifically reported. Finally, 30 peer-reviewed abstracts or presentations for professional organization events, or peer-reviewed journal publications, were specifically reported, with an additional 5 in varying states of preparation. These examples demonstrate that some students were able to conduct meaningful research as measured by presentation of their research using the PBDB at local, regional, and national conferences and publication in peer-reviewed journals.

\section{Discussion}

Broadly, according to the inquiry-based activity survey results, students reported positive attitudes toward research in general and intrinsic sources of motivation to engage in research. This is consistent with what others have found about student attitudes toward research (e.g., Lopatto 2004; Mabrouk and Peters 2000; Seymour et al. 2004). However, much of that work has been conducted with students who have already identified as STEM majors. More specifically, with the majority of students reporting they would want to use the PBDB to conduct their own research project (61 percent in activity reflections) and their intent to do a research or creative project with a faculty member (45 percent in the survey), the results suggest that students do have a general interest in using a large dataset such as PBDB to engage in research. This holds promise for student interest in the use of other large research databases as well. However, activity reflection responses suggest student definitions and mental models of "research" are limited and should be further explored. These open-ended written responses suggest mental models in which research consists of finding and summarizing existing "facts" about a phenomenon rather than constructing new knowledge. Additionally, responses suggest that student understanding of how a database can be used to conduct independent research remains unclear. Responses tended to mimic the nature of the class activity with the PBDB. For example, students completing the extinction rate activity had a higher frequency of responses that described using PBDB to conduct a research project to look at extinction and survival rates of organisms over time. This parroting of lesson objectives suggests that more explicit instruction around what research is and what it means to conduct research is needed in inquiry-based activities to ensure a quality experience and support students identifying as researchers.

\section{Limitations, Lessons Learned, and Implications}

Activity reflection questions and survey response data have implications for future related investigations. The data represent snapshots of student perceptions at two discrete points of time within a semester and course. It remains unclear whether student perceptions of skill development and interest in research resulting from work with the PBDB are sustained beyond the immediacy of the course. Future investigations would benefit from including a longitudinal component to determine if these perceptions persist over time. Additionally, most students only experienced one activity per course. Questions remain about whether curriculum design that includes a sustained engagement with these activities over the semester would result in different or more lasting perceptions. The undergraduate research community would benefit from studies that examine the impact of such repeated or sustained engagement.

Student responses to the activity reflection questions also demonstrate a need for researchers to investigate student mental models and misconceptions of the definition and nature of research. For practitioners, these responses demonstrate a need for intentional instruction around what research is and looks like in practice (e.g., formulating hypotheses and testing hypotheses), particularly if the goal is to encourage and prepare students to conduct independent research with databases and other tools like the PBDB. In terms of broader learning activity and curriculum development, this project provides a successful process model for developing activities that are aligned to learning objectives and that leverage large databases. This can include inquiry-based activities using other large geoscience databases on topics such as earthquakes (USGS n.d.a), water levels (USGS n.d.b), stratigraphy (Macrostrat n.d.), recent paleoecology (Neotoma n.d.), and climate (NOAA n.d.).

It was clear from responses to the independent research experience survey that further probing using a focus group or one-on-one interviews directly with students would be beneficial. Survey responses indicated that faculty respondents were also operating under a variety of definitions of research. For example, one of the projects described consisted only (as written) of the student entering data into the database. The descriptions of class and collaborative projects suggest a guided inquiry experience in which students were given a specific guiding question and hypothesis, rather than being responsible for creating their own research question or determining which data were needed from the database. A follow-up survey was created that included, among other items, CUR's definition of research, "an inquiry or investigation conducted by an undergraduate student that makes an original intellectual or creative contribution to the discipline" (Council on Undergraduate Research n.d.). The revised survey also included a clarifying question that asked how the students specifically used the PBDB. The previous participants were asked to complete this new follow-up survey, but no 
one completed the revised survey, likely due to timing (the end of spring semester, a busy time for faculty) and survey fatigue (participants had been asked previously to complete other surveys for the PBDB project). Future investigations would benefit from using the revised survey or an interview format to ensure clarity regarding the participants' views of research and to determine the specific nature of student work. The survey also did not ask faculty to report on how they mentored students about conducting large database research, or PBDB specifically. This line of questioning may provide insights into how faculty can successfully support students conducting research using database tools. Although not all student work met the criteria of success as reported in the survey, it is clear from the number of projects presented at professional or peer-reviewed conferences or published in peer-reviewed journals (30) that students can successfully engage in publication-quality independent research using the PBDB. This indicates that using other large databases to conduct independent research may similarly result in success. Unfortunately, examples of independent research projects that were completed as part of a 100-percent online program were not collected. It remains unclear, therefore, what the outcomes would be of a program conducted entirely online.

While not the focus of this study, the data provide some unexpected insight into the levels of student participation in undergraduate research experiences that warrant further investigation. The fact that only two people reported that nothing would motivate them to participate in a research project but only 45 percent of students reported that they were participating or planning to participate in a research project suggests the presence of barriers between being motivated to undertake undergraduate research experiences and actually participating. The overwhelming majority of students (76 percent, $n=263$ ) responded that they would be motivated if they were "working on a specific project of interest." It would be beneficial, therefore, for future studies to examine how students engaged in undergraduate research experiences discovered their project of interest. The second most commonly reported source of motivation (71 percent) was "gaining experience for career or graduate school," suggesting that faculty mentors and instructors might increase student participation in undergraduate research by more explicitly communicating the value and application of participation to graduate school and career goals. It is also noteworthy that less than half of respondents (45 percent) reported that they would be motivated by "receiving compensation or pay" to engage in research. This suggests that intrinsic motivators outweighed extrinsic motivators like compensation and/or that these students had less economic need.

\section{Future Plans}

Future research plans include possible follow-up with the independent research project participants and their faculty mentors to examine more closely the specifics of their research and mentoring experience, so that a model can be described and reported for others to use. Additionally, it would be beneficial to identify an independent research project that was completed as part of an online program and evaluate the outcomes.

\section{Acknowledgments}

This research is funded by the National Science Foundation (NSF) Grant \#DUE-1504588. The PBDB is primarily supported by NSF EAR Geoinformatics grant 0949416. The opinions and interpretations made here belong to the authors and do not represent the NSF.

\section{References}

Baker, Margaret A. 2006. Status Report on Geoscience Summer Field Camps (Report GW-06.003:8). Washington, DC: American Geological Institute.

Bernard, Rachel E., and Emily H. G. Cooperdock. 2018. "No Progress on Diversity in 40 Years." Nature Geoscience 11: 292-295. doi: 10.1038/s41561-018-0116-6

Birnbaum, Stuart. 2004. "Overcoming the Limitations of an Urban Setting through Field-Based Earth Systems Inquiry." Journal of Geoscience Education 52: 407-410. doi: 10.5408/10899995-52.5.407

Buck, Laura B., S. Lowery Bretz, and Marcy H. Towns. 2008. "Characterizing the Level of Inquiry in the Undergraduate Laboratory." Journal of College Science Teaching 38(1): 52-58.

Carabajal, Ivan G., Anita M. Marshall, and Christopher L. Atchison. 2018. "A Synthesis of Instructional Strategies in Geoscience Education Literature That Address Barriers to Inclusion for Students with Disabilities." Journal of Geoscience Education 65: 531-541. doi: 10.5408/16-211.1

Carleton College. n.d. "Science Education Resource Center (SERC)." https://serc.carleton.edu/index.html

Council on Undergraduate Research. n.d. "About CUR." Accessed August 2015. https://www.cur.org/about_cur

Drummond, Carl N. 2001. "Can Field Camps Survive?" Journal of Geoscience Education 49: 336-338.

Foster, Stephanie L., and Bethany M. Usher. 2018. "Comparing Two Models of Undergraduate Research Using the OSCAR Student Survey." Scholarship and Practice of Undergraduate Research 1(3): 30-39. doi: 10.18833/spur/1/3/6

Gorden, Raymond L. 1992. Basic Interviewing Skills. Itasca, IL: Peacock.

Hurst, Stephen D. 1998. "Use of 'Virtual' Field Trips in Teaching Introductory Geology.” Computers \& Geosciences 24: 653-658. doi: 10.1016/s0098-3004(98)00043-0

InTeGrate. 2016. "Your Module/Course Development Timeline." Accessed May 17, 2016. https://serc.carleton.edu/integrate/ info_team_members/currdev/timeline.html

Kean, William F., and Larry G. Enochs. 2001. "Urban Field Geology for K-8 Teachers." Journal of Geoscience Education 49: 358-363. doi: 10.5408/1089-9995-49.4.358 
Lockwood, Rowan, Phoebe Cohen, Mark D. Uhen, and Katherine Ryker. 2018. "Utilizing the Paleobiology Database to Provide Educational Opportunities for Undergraduates." In Elements of Paleobiology, ed. Phoebe Cohen, L. Park Boush, and Rowan Lockwood, 1-18. Cambridge, UK: Cambridge University Press. doi: $10.1017 / 9781108681667$

Lopatto, David. 2004. "Survey of Undergraduate Research Experiences (SURE): First Findings." Cell Biology Education 3: 270-277. doi: 10.1187/cbe.04-07-0045

Mabrouk, Patricia Ann, and Kristen Peters. 2000. "Student Perspectives on Undergraduate Research (UR) Experiences in Chemistry and Biology." CUR Quarterly 21(1): 25-33.

Macrostrat. n.d. https:// https://macrostrat.org/

National Academies of Sciences, Engineering, and Medicine. 2016. "Barriers and Opportunities for 2-Year and 4-Year STEM Degrees: Systemic Change to Support Students' Diverse Pathways." Accessed June 2018. http://www.nap. edu/catalog/21739/barriers-and-opportunities-for-2-year-and4-year-stem-degrees

National Academies of Sciences, Engineering, and Medicine. 2017. Undergraduate Research Experiences for STEM Students: Successes, Challenges, and Opportunities. Washington, DC: National Academies Press. doi: 10.17226/24622

National Academies of Sciences, Engineering, and Medicine. 2018. Indicators for Monitoring Undergraduate STEM Education. Washington, DC: National Academies Press. doi: $10.17226 / 24943$

National Centers for Environmental Information, National Oceanic and Atmospheric Administration (NOAA). n.d. "Climate Data Online." https://www.ncdc.noaa.gov/cdo-web/

National Research Council. 2000. Inquiry and the National Science Education Standards. Washington, DC: National Academies Press.

Neotoma Paleoecology Database. n.d. https://www.neotomadb. org/about/category/about

Paleobiology Database (PBDB). n.d.a https://paleobiodb.org/

Paleobiology Database (PBDB). n.d.b. "Resources." https:// paleobiodb.org/\#/resources

Ryker, Katherine, and David McConnell. 2014. "Can Graduate Teaching Assistants Teach Inquiry-Based Geology Labs Effectively?" Journal of College Science Teaching 44: 56-63.

SALG (Student Assessment of Learning Gains). 2013. "About SALG." Accessed August 2015. http://www.salgsite.org/about

Seymour, Elaine, Susan M. Daffinrud, Douglas J. Wiese, and Anne-Barrie Hunter. 2000. "Creating a Better Mousetrap: Online Student Assessment of Their Learning Gains." National Meeting of the American Chemical Society, San Francisco, CA.

Seymour, Elaine, Anne-Barrie Hunter, Sandra L. Laursen, and Tracee DeAntoni. 2004. "Establishing the Benefits of Research Experiences for Undergraduates in the Sciences: First Findings from a Three-Year Study." Science Education 88: 493-534. doi: $0.1002 /$ sce. 10131

12 Scholarship and Practice of Undergraduate Research
Singer, Susan R., Natalie R. Nielsen, and Heidi A. Schweingruber (Eds.) 2012. Discipline-Based Education Research: Understanding and Improving Learning in Undergraduate Science and Engineering. Washington, DC: National Academies Press.

Strauss, Anselm, and Juliet Corbin. 1998. Basics of Qualitative Research: Techniques and Procedures for Developing Grounded Theory. Thousand Oaks, CA: SAGE. doi: $10.4135 / 9781452230153$

Tewksbury, Barbara. 2011. "Peer Review of Teaching Activities Rubric." On the Cutting Edge. Accessed June 9, 2019. https://d32ogoqmya1dw8.cloudfront.net/files/NAGTWorkshops/ intro08/rubric_review_others_assignmen.pdf

Uhen, Mark D. 2014. "Paleobiology Database: A Community Based Data Service for Paleobiology." Geological Society of America Abstracts with Programs 46(2): 700.

Uhen, Mark D. 2015. "Paleobiology Database: Using Data from the Past to Expand Research and Educational Opportunities for the Future." Geological Society of America Abstracts with Programs 47(7): 613 .

Uhen, Mark D. 2016. "Integrating Paleontological and Neontological Data across Time and Space." Geological Society of America Abstracts with Programs 48(7): 105-109. doi:10.1130/ abs/2016am-285799

US Geological Survey (USGS). n.d.a. "Earthquake Hazards Program." https://earthquake.usgs.gov/

US Geological Survey (USGS). n.d.b."National Water Information System: Web Interface." https://waterdata.usgs.gov/nwis/sw

Whitmeyer, Steven J., David W. Mogk, and Eric J. Pyle (Eds.) 2009. Field Geology Education: Historical Perspectives and Modern Approaches. Boulder, CO: Geological Society of America. doi: $10.1130 /$ spe 461

\section{Laura A. Lukes}

George Mason University, llukes@gmu.edu

Laura Lukes is a geologist and geoscience education researcher who serves as assistant director of the Stearns Center for Teaching and Learning at George Mason University (GMU). Her research focuses on how learning environments, teaching practices, and beliefs influence the strategies and tactics used by students to manage their own learning in classroom settings (self-regulated models of learning). She previously served as an Albert Einstein Distinguished Educator Fellow in the Office of Polar Programs at the National Science Foundation, president of the Geoscience Education Research Division (GER) of the National Association of Geoscience Teachers (NAGT), and chair of the Education Committee of the Geological Society of America (GSA). Lukes was awarded the 2017 Biggs Award for Excellence in Earth Science Teaching from GSA and named a GSA Fellow.

Katherine Ryker is an assistant professor in the School of the Earth, Ocean, and Environment at the University of South Carolina. Her research interests primarily revolve 
around classroom interventions in introductory geoscience labs (including through augmented and virtual reality tools), connecting teaching beliefs and practices, and teaching professional development. She served as the NAGT GER secretary from 2014 to 2017 and as vice president from 2017 to2018.

Camerian Millsaps served as an undergraduate research assistant in GMU's Department of Atmospheric, Oceanic, and Earth Sciences for this project. She is currently a graduate student at Arizona State University.

Rowan Lockwood is a professor of geology at the College of William \& Mary whose research focuses on the effects of environmental change (including asteroid impacts, global warming, ocean acidification, and anoxia) on life in ancient oceans. She has published 30 peer-reviewed papers in journals such as Science and Nature, and has been awarded numerous grants totaling more than $\$ 1.2$ million. Since 2001, Lockwood has taught more than 3,400 undergraduates in 48 classes, ranging from general education courses and first-year writing seminars to upperlevel field-and lab-intensive courses, and mentored more than 70 undergraduate researchers.

Mark D. Uhen is an associate professor of geology and associate chair of the Department of Atmospheric, Oceanic, and Earth Sciences at GMU. His research focuses on the origin and evolution of cetaceans (whales and dolphins), major evolutionary transitions in general, functional morphology, use of stratigraphic data in phylogenetic analysis, and theoretical aspects of diversification. Uhen also is a research associate at the US National Museum of Natural History and the chair of the Executive Committee of the Paleobiology Database. He previously was curator of paleontology at the Alabama Museum of Natural History and head of research and collections at Cranbrook Institute of Science. Uhen has received research grants from the National Science Foundation, National
Geographic Society, and the US National Museum of Natural History.

Christian O. George is an assistant professor in the Department of Biology at High Point University. He previously was a term assistant professor in GMU's Department of Atmospheric, Oceanic, and Earth Sciences. George's research and teaching focus on the evolutionary history of life on earth. As a paleoecologist, he investigates the correlation between past climate and ancient mammalian communities through the analysis of large paleontological databases such as NEOTOMA and the PBDB.

Callan Bentley is an assistant professor of geology at Northern Virginia Community College's Annandale campus who teaches mainly physical geology and historical geology in two introductory courses on the composition, function, and history of Earth. He writes the geology blog Mountain Beltway. Bentley has served as newsletter editor for the Geo2YC division of the National Association of Geoscience Teachers and the eastern section of NAGT and is the president of the Geo2YC and the president of the Geological Society of Washington (GSW). He previously served GSW as councilor, meeting secretary, executive secretary, and vice president.

Peter Berquist is an assistant professor and the department chair of geology at Thomas Nelson Community College in Williamsburg, Virginia. He coauthored an InTeGrate module on carbon, climate, and energy resources; serves on the executive board of the National Association of Geoscience Teachers 2YC Division; and leads workshops for the NAGT Traveling Workshop Program. He has been involved in the Supporting and Advancing Geoscience Education (SAGE) program since 2013, offering professional development workshops for geoscience faculty and promoting efforts to broaden participation within the geosciences, increase student success, and facilitate transfer to academic and professional avenues for geoscience students. 